\title{
Transformações na atenção em saúde mental e na vida cotidiana de usuários: do hospital psiquiátrico ao Centro de Atenção Psicossocial*
}

Transforming Mental Health Care and users' everyday life: from the psychiatric hospital to the Psychosocial Care Center

Mariana Moraes Salles', Sônia Barros²

' Doutora em Cuidado em Saúde pela Universidade de São Paulo (USP) - São Paulo (SP), Brasil. Professora temporária do Departamento de Enfermagem Materno-Infantil e Psiquiátrica da Escola de Enfermagem da Universidade de São Paulo (USP) - São Paulo (SP), Brasil.

marianasalles@uol.com.br

2 Doutora em Enfermagem pela Universidade de São Paulo (USP) - São Paulo (SP), Brasil Professora titular do Departamento de Enfermagem Materno-Infantil e Psiquiátrica da Escola de Enfermagem da Universidade de São Paulo (USP) - São Paulo (SP), Brasil. sobarros@usp.br
RESUMO Objetivou-se identificar os processos de exclusão/inclusão social de usuários de um Centro de Atenção Psicossocial (CAPS) em relação aos diferentes modelos de atenção à saúde. Utilizou-se a abordagem qualitativa como metodologia de pesquisa. Para a coleta de dados foram entrevistados usuários do CAPS e pessoas de sua rede social, e para apuração dos dados foi utilizada a análise do discurso. Os usuários podem passar longos períodos segregados nos manicômios, desaparecendo do cenário das cidades. Porém, o CAPS é um lugar de acolhimento, o primeiro espaço social e subjetivo em que os usuários podem ser quem são e procurar caminhos para uma vida cotidiana em sociedade.

PALAVRAS CHAVE: Saúde Mental; Reforma dos Serviços de Saúde; Desinstitucionalização; Participação Social; Serviços de Saúde Mental.

ABSTRACT This study aims at identifying the process of social exclusion/inclusion of users of a Psychosocial Care Center (CAPS), in comparison to different models of health care. The qualitative approach was used as the research methodology. For data gathering users and people from their social network were interviewed and discourse analysis was used for examining the data. The users can stay long periods shunned in the asylums, disappearing of the city landscape. However, CAPS is a welcoming place, the first social and subjective space in which the users can be how they are and search for ways for everyday life in society.

KEYWORDS: Mental Health; Health Care Reform; Deinstitutionalization; Social Participation; Mental Health Services.

- Artigo baseado em parte da tese de doutorado de Mariana Moraes Salles, apresentada ao Programa de Pós-Graduação em Cuidado em Saúde da Escola de Enfermagem, Universidade de São Paulo, em 2011. 


\section{Introdução}

As pessoas que vivenciam o adoecimento mental têm uma história de vida única, constituída pelos detalhes da sua vida cotidiana, em um desdobramento de fatos que distinguem diferentes fases da vida. $\mathrm{O}$ transtorno mental é um fato marcante na vida das pessoas, pois são desencadeadas mudanças no cotidiano, transformando o que estas pessoas fazem; como e com quem se relacionam, e seus projetos de vida.

Porém, essa história de vida está inserida em uma história maior, na história da sociedade em que essa pessoa vive. Como nas engrenagens de um relógio, os cotidianos de vida individuais constituem e são constituídos pelo cotidiano da sociedade em que se vive. Assim, as pessoas com transtornos mentais se percebem inseridas em uma história social marcada pela exclusão da loucura, e veem seu cotidiano e sua história de vida particular transformada pelas marcas do preconceito e da discriminação.

Essas pessoas têm suas histórias de vida alteradas pela história do tratamento em saúde mental; pelas formas da sociedade pensar e lidar com a loucura, que oscilam entre o modo asilar e o modo psicossocial.

No modo asilar, o indivíduo é visto como doente, e o tratamento ocorre por meio de fármacos. As relaçôes institucionais são piramidais ou verticais, poucos dominam e a maioria obedece. O poder e o saber são estratificados, os usuários estão excluídos de qualquer participação que não seja de objeto inerte e mudo. As relaçóes se estabelecem entre os loucos e os sãos, a razão e a insensatez (COSTA-ROSA, 2000). O doente mental é um excluído que, conforme o contexto histórico, “[...] jamais poderá opor-se a quem o exclui, porque todo o seu ato está circunscrito e definido pela doença” (BASAGLIA, 2005a, p. 38).

Esta necessidade de

[...] dividir, de isolar, de afastar o doente mental, expressa também o estado de debilidade e de amesquinhamento de uma sociedade que tende a eliminar o que perturba sua expansão, sem levar a responsabilidade que também lhe cabe nestes processos. (BASAGLIA, 2005a, p. 47).

Porém, no atual contexto histórico, os usuários têm vivenciado novas formas de atenção e relacionamento com a sociedade. Existe um movimento social de transformação, que possibilita criar modificaçóes no contexto das pessoas com transtornos mentais.

No modo psicossocial, a loucura é considerada um fenômeno social, o sofrimento psíquico não tem que ser removido, mas sim integrado como parte da existência da pessoa. A ênfase é dada à reinserção social e à recuperação da cidadania (COSTA-ROSA, 2000).

O termo exclusão social é frequentemente usado como consequência de privação material e restrição de oportunidades, mas não podemos esquecer que a exclusão social é um termo multidimensional, relacionado à falta de participação em atividades sociais, culturais, econômicas e políticas (MORGAN et al, 2007). Não é simples transformar a longa história de exclusão vivenciada pelas pessoas com transtornos mentais.

\section{A tradição possui uma força imensa, sobretudo no que se refere à vida cotidiana, aos sistemas consuetudinários e a todos carecimentos ligados a tais sistemas. São elementos que passam de geração para geração. (HELLER, 1982, p. 137).}

Nesse contexto, o Centro de Atenção Psicossocial (CAPS) é um serviço que deve favorecer os processos de inclusão social das pessoas com transtornos mentais, atuando no território, constituindo uma rede de pessoas e serviços que, juntos, possam se fortalecer e enfrentar o desafio de transformar o cotidiano das pessoas (sejam os usuários, os profissionais ou pessoas da rede social dos usuários) e o cotidiano das instituiçóes, serviços de saúde e de outros setores sociais.

As pessoas que se mobilizam para transformar a história da relação da sociedade com o transtorno mental estão também revendo a sua própria forma de estar no mundo. Afinal, segundo Heller (1982, p. 154) “[...] 
se agimos, somos responsáveis pelo que se realiza através da nossa ação; se nos afastamos da ação, somo responsáveis pelo que não fizemos".

Assim, os objetivos do presente estudo foram identificar os processos de exclusão/inclusão social que os usuários vivenciaram em sua vida cotidiana, em relação aos diferentes modelos de atenção à saúde para essa população.

\section{Metodologia}

Utilizou-se a abordagem qualitativa como metodologia de pesquisa, que se propóe a considerar a realidade em sua complexidade, refletindo sobre a maneira como as pessoas vivem a sua vida, se referindo ao processo histórico em que se desenvolvem suas bases materiais, relaçóes sociais e ideologia.

Como referencial filosófico de suporte para o desenvolvimento da pesquisa foi utilizada a teoria sobre o cotidiano de Ágnes Heller, que considera que "[...] a história é a substância da sociedade" e aos homens cabe a construção e a transmissão da estrutura social, que contêm a continuidade de toda a heterogeneidade da estrutura social e a continuidade de valores (HELLER, 2000, p. 2).

É nesse processo histórico que os homens se constituem, aprendendo com o que é posto pela sociedade, com o passado que foi construído, e criando novas possibilidades para o futuro.

A história é substância social em desenvolvimento, é estruturada e heterogênea, encontrando-se em diferentes esferas. A sociedade é sempre um complexo determinado, "[...] com um método de produção determinado, apresentando ainda classes, camadas, formas mentais e alternativas determinadas" (HELLER, 2000, p. 12).

Os sujeitos desta investigação foram pessoas com transtorno psíquico, usuários de um CAPS II na região oeste de São Paulo, que estavam vivendo na comunidade e enfrentando o desafio da inclusão social e de construir uma vida significativa, além de pessoas de sua rede social.

Foi solicitado ao diretor do serviço que realizasse uma caracterização do mesmo e identificasse açóes do CAPS que têm como objetivo promover a inclusão social. Foram indicadas quatro oficinas com o objetivo de promover a inclusão social dos usuários do CAPS: a oficina Recicla Tudo, a oficina de Panificaçáo, a oficina de Brechó e o grupo Criativa.

Dentre os usuários do CAPS que participavam dessas açóes foram selecionados aqueles: matriculados há pelo menos um ano na instituição; conscientes, orientados no espaço e tempo, sem déficit cognitivo moderado ou grave, capazes de compreender e responder a perguntas; que concordaram e se dispuseram a participar da pesquisa, e que estiveram presentes nos dias da coleta de dados.

Também foram entrevistadas pessoas indicadas pelos usuários, por serem significativas para a inclusão social do sujeito com transtorno mental, que fazem parte de sua rede de relacionamentos e suporte social. Foram realizadas, no total, 29 entrevistas: 17 com usuários e 12 com pessoas de sua rede de relaçóes sociais.

Dos usuários entrevistados, dois haviam passado mais de dez anos internados; cinco já haviam sido internados mais de dez vezes; quatro haviam vivenciado de três a seis internaçóes em hospitais psiquiátricos; quatro tinham sido internados apenas uma ou duas vezes; e dois nunca haviam sido internados. Todos os usuários entrevistados tiveram a experiência de atenção em um CAPS.

Para a coleta de dados foram realizadas entrevistas semiestruturadas, que oferecem perspectivas "[...] possíveis para que o informante alcance a liberdade e a espontaneidade necessárias, enriquecendo a investigação" (TRIVIÑOS, 1987, p. 146).

O CAPS, cenário do estudo, foi informado sobre os objetivos, as finalidades e os procedimentos metodológicos do estudo e concordou com o desenvolvimento da pesquisa no local. O projeto foi aprovado também pelo Comitê de Ética e Pesquisa da Secretaria Municipal de Saúde, que autorizou o desenvolvimento da pesquisa.

Os entrevistados assinaram um termo de consentimento livre e esclarecido, autorizando a utilização dos dados coletados na referida pesquisa, e foi garantido sigilo sobre a identidade dos entrevistados.

Para apuração dos dados foi utilizada a análise do discurso. Os discursos estão relacionados com a cultura de uma sociedade, reproduzindo o que um grupo social tem a dizer; os homens se identificam com o que 
dizem e, nesse processo, se constroem enquanto sujeitos (VIANNA; BARROS, 2003).

O sujeito seleciona o que diz e essa escolha está relacionada com a maneira pela qual ele é

[...] afetado pela ideologia; sua maneira de ordenar, classificar e explicar a ordem social. A análise do discurso permite uma compreensão mais profunda do texto de acordo com a realidade social e histórica na qual foi produzido. (VIANNA; BARROS, 2003, p. 59).

Neste trabalho, após a coleta de dados, as entrevistas foram transcritas na íntegra, constituindo um texto para análise. Após a transcrição, leitura e releitura das entrevistas, o texto foi organizado em "[...] frases temáticas imbuídas de afinidades em cada entrevista" (BARROS; EGRY, 2001, p. 105).

Após essa etapa, foi realizado um trajeto temático, procurando agrupar os fragmentos pelos temas a que se referem, reunindo os trechos temáticos similares de todos os depoimentos. A partir dessa tematização, o texto foi revisto, com vistas a encontrar afinidade e conexão entre os temas, para então se definirem as categorias empíricas inerentes ao discurso. Foram identificadas as seguintes categorias empíricas: processo de exclusão/inclusão social, redes sociais e cuidado em saúde mental. O presente artigo trata da categoria empírica cuidado em saúde mental.

\section{Resultados e discussão}

\section{Hospitais psiquiátricos: uma história de exclusáo social}

Historicamente, a sociedade tem lidado com a loucura excluindo as pessoas com transtornos mentais de seu contato diário. Elas são banidas para espaços de reclusão, sendo isoladas e privadas do convívio da sociedade. Nesse contexto, os hospitais psiquiátricos têm cumprido esse papel de recolher as pessoas com transtornos mentais, com o argumento de oferecer um tratamento que supostamente melhora a saúde dessas pessoas.
Segundo Saraceno (2001, p. 63), o hospital psiquiátrico é o lugar continente da ideologia psiquiátrica, e "[...] continua como signo da continuidade histórica do cerco à desrazão iniciado com o primeiro manicômio muitos séculos atrás. A história continua”. Mudam formas, linguagens e competências, mas o processo de cerco à loucura e exclusão à desrazão continua. O manicômio é uma variável independente das condições socioeconômicas do país onde se encontra, é o lugar destinado a zerar a troca.

Atualmente, os serviços de internação são constituídos para atender o momento de crise da pessoa com transtorno mental, oferecendo suporte e contenção temporários, até que a pessoa se estabilize e retome sua vida cotidiana.

Entretanto, muitos dos hospitais psiquiátricos não cumprem apenas a função de atender a crise, como um serviço a ser utilizado por um período curto de tempo. As pessoas com transtornos mentais podem passar longos períodos fisicamente excluídas da sociedade, segregadas e isoladas nos manicômios, desaparecendo do cenário das cidades.

$\mathrm{Na}$ internação por longo tempo, a vida das pessoas com transtornos mentais passa a ser a vida do hospital, o cotidiano do indivíduo é regido pelo cotidiano no hospital. O hospital se torna a 'casa' da pessoa com transtorno mental, sua vida gira em torno das atividades do hospital; há o rompimento com a vida em sociedade, como se eles não existissem para o mundo fora do hospital.

O doente é forçado a aderir a um novo corpo, que é o da instituição. A ele é negado qualquer

[...] desejo, qualquer ação, qualquer aspiração autônoma que o faria sentir-se ainda vivo e ainda ele mesmo. Torna-se um corpo vivido na instituição, pela instituiçâo, a ponto de ser considerado como parte integrante das próprias estruturas físicas desta. (BASAGLIA, 2005b, p. 80).

Alguns entrevistados relatam suas experiências no manicômio, como se vê nas frases que se seguem: 
U5 fr 49': Mas eu gostava de morar lá [hospital psiquiátrico]. Tinha sabonete, creme dental, sapato, calça. Eu morei 40 anos, minha casa era lá.

R3 fr 37: Mas depois que ele ficou internado, acho que ele ficou oito anos internado.

As pessoas que passam a vida nos hospitais psiquiátricos acabam se apropriando do cotidiano do hospital, criam uma forma de viver própria dentro do manicômio, tentando trazer significado para as suas vidas e para as atividades que realizam no hospital.

Para alguns internos, a participação nas atividades do hospital representa a possibilidade de permanecer em um local com um pouco mais liberdade (principalmente, nas atividades ao ar livre). Além disso, realizar uma tarefa proposta pelo hospital é um recurso dos internos para iniciar uma forma de boas relaçóes com a equipe dirigente e estar em posição para ter acesso ao fruto de seu esforço. Por exemplo, ao trabalhar na horta, a pessoa tem acesso a frutas e outros alimentos (GOFFMAN, 2003).

U5 fr 6: [Sobre periodo de internação] Trabalho. Eu trabalho. Planta na plantação. Colhe. Entrega pro dono. Verdura... Pra cozinhar. E ai, faz comida pra turma, né?

U5 fr 45: Depois, eu virei meio funcionário de lá. Eu fazia café, buscar coisas, lavava latão. Tinham 500 pessoas.

Além das internaçóes por longo tempo, também foram relatadas as internaçóes múltiplas, nas quais a pessoa com transtorno mental entra e sai dos hospitais psiquiátricos repetidas vezes, sem conseguir se estabelecer na comunidade.

A reabilitação psicossocial pressupóe que a comunidade e a atenção à saúde mental sejam dimensóes possíveis de propiciar a inserçẫo social do paciente.
Mas o grande número de reinternaçóes em hospitais psiquiátricos vai de encontro com os pressupostos da Reabilitação Psicossocial e da Reforma Psiquiátrica. (SALLES, 2005, p. 27).

$\mathrm{Na}$ lógica do revolving door, há a substituiçãao da segregação estática em uma instituição total por uma dinâmica de circulação em serviços especializados com uma atenção pontual e fragmentada, ocorrendo um jogo de alimentação recíproca. Os locais de internação representam, neste circuito, um ponto de descarga necessário, temporário e recorrente (ROTELLI; LEONARDIS; MAURI, 2001, p. 23).

Assim, é fundamental uma rede de serviços forte e atuante no território, trabalhando na lógica da intersetorialidade, para criar espaços sociais para essas pessoas.

U7 fr 23: [Sobre o dia a dia antes de frequentar o CAPS] Era muita internação, que quando atacava a cabeça, ai, internava eu. Minha ex-mulher internava eu, internava eu.

R7 fr 11: Ele foi internado, que vê, no Jaçanã; em Guarulhos, uma porção de vezes. Dai, foi internado no hospital psiquiátrico de Mandaqui, no hospital psiquiátrico de Vargem Paulista, lá naquela lonjura... Qual outro... Também foi internado lá em Atibaia, mas lá eu não fui visitar ele.

Há um conjunto de circunstâncias que ajudam a determinar quando o usuário receberá alta, como o desejo da família para que a pessoa volte ao convívio familiar (GOFFMAN, 2003).

É ressaltada a importância de a família receber suporte dos serviços de saúde mental, favorecendo que a pessoa com transtornos mentais encontre apoio no seu ambiente social. De acordo com Borba, Schwartz e Kantorski (2008, p. 593), a família não interna o

' A letra U é um símbolo de referência para usuário e a letra R, para pessoas da rede social dos usuários. A sigla fr refere-se à frase e ao número da frase do entrevistado. Assim, 'U 5 fr 49' significa usuário número 5, frase número 49. 
usuário por não ser responsável ou não o amar, mas porque se tornou insustentável e desgastante a convivência com a pessoa com transtorno mental.

\section{U5 fr 44: Fiquei internado lá no hospital cen- tral, em Franco da Rocha. Porque a turma não vinha buscar eu, então eu fiquei muito tempo lá [40 anos].}

No modelo centrado no hospital psiquiátrico, a família pode compreender que cuidar da pessoa com transtorno mental significa ir visitá-lo no hospital, sem pensar em possibilidades de tratamento na comunidade.

Segundo dados do Censo Psicossocial de moradores em hospitais psiquiátricos do Estado de São Paulo, $50 \%$ dos familiares de moradores de hospitais psiquiátricos "[...] procuravam as pessoas moradoras de forma eventual - mensal ou semanal, mas parecem não se dispor a recebê-las" (BARROS; BICHAFF, 2008, p. 98).

Ainda que a família entenda que visitar signifique manter o relacionamento com o usuário, estabelecendo uma continuidade na relação mesmo em momentos de crise, é possível que a família minimize a importância do seu papel e não encontre suporte social e de serviços de saúde para conseguir romper com o ciclo de reinternaçóes.

Nesse sentido, prevalece a lógica de que tratar o usuário é interná-lo, sem se estabelecer possibilidades de cuidado em casa, na família, na comunidade, com apoio de serviços abertos. Para que esse cuidado aconteça, é importante que os familiares conheçam e confiem em modelos de atenção substitutiva ao hospital psiquiátrico.

R7 fr 10: Mas quando ele estava internado, $o$ hospital mandava me buscar. Ai, eu ia no hospital, levava as coisas, cuidava. Mas quando ele tinha alta do hospital e vinha para casa de novo, com dois ou três dias, ele sumia. E assim, foi minha vida durante 40 anos.

A internação prolongada, ou a sequência de reinternaçôes, pode ser a consequência ou a causa do rompimento de laços com familiares. Entretanto, quanto mais tempo a pessoa com transtorno mental permanece internada, maior a probabilidade dos relacionamentos com os familiares e com outras pessoas da sociedade se tornarem frágeis, resultando no seu isolamento.

U5 fr 56: Eu me senti alegre com isso [trabalho em oficina no hospital], mas estava aborrecido, porque estava longe da familia. Era muito tempo sem ver a família.

R13 fr 26: E eu imagino que, em algum momento, ele se lembrou de toda essa vivência dele, e estar num lugar daqueles, longe dos amigos, da família, das pessoas que ele gosta, que ama...

Contraditoriamente, o hospital psiquiátrico pode ser entendido com espaço de albergamento. Frente ao desamparo e à falta de suporte na comunidade, as pessoas com transtornos mentais podem considerar o hospital psiquiátrico como um local de asilamento. Nesse contexto social de exclusão, pensar em sair da internaçáo pode representar o enfrentamento da angústia da exclusão vivida na sociedade, pois, sem suporte familiar ou social, essas pessoas podem se ver em uma situação difícil.

Por isso, a importância dos programas de atenção em saúde mental relacionados à moradia, como os programas de residência terapêutica, que criam um novo espaço de acolhimento para essas pessoas reconstruírem suas vidas na sociedade. Para aqueles que não podem contar com a família para recebê-los após uma internação, a questão da moradia é primordial para a sua inclusão social.

Com o fechamento dos hospitais psiquiátricos, as pessoas precisam encontrar arranjos individuais de moradia, participação na comunidade e uma ocupação significativa. O velho hospital pode ter fechado, mas a transformação ainda não está completa (DAVIS, 2002, p. 54). De acordo com Amarante (2007, p. 88), após as dificuldades passadas no hospital psiquiátrico, a maioria das pessoas com transtornos mentais não tem condição de 
[...] voltar a viver sem ajuda de terceiros $e$, por isso, é muito importante que sejam organizados programas e estratégias de apoio psicossocial para estas pessoas, dentre as quais as estratégias residenciais e de subsidios financeiros.

U14 fr 17: Sobre aquele negócio de hospital psiquiátrico fechado e hospital aberto... Sem dúvida, melhorou para uns. Para uns, melhorou bem; para aqueles que têm sua casa para morar, têm onde ficar.. Mas tem muita gente que não é bem assim... No hospital fechado, ele já tava abrigado; tem casa, comida, roupa lavada. As vezes, eles vão para o hospital psiquiátrico e nem tá muito doente, né?

U7 fr 24: Tinha internação sempre, ficava mais tempo internado que fora, porque eu não tinha casa. Eu morei na rua também, morei na rua dois anos.

Essas frases desvelam que a inclusão social das pessoas com transtornos mentais é muito mais uma questão de suporte social do que de promover remissão de sintomas.

Muitos dos usuários passaram por repetidas internações, e foram relatadas críticas em relação à falta de atenção à pessoa em sofrimento psíquico que ocorre nos hospitais psiquiátricos, ressaltando que a internação psiquiátrica faz parte de um processo de marginalizaçáo e perda de direitos sociais. Essa falta de atenção e cuidado com as pessoas com transtornos mentais internadas torna o momento da crise ainda mais difícil e a relação com a doença mais complicada.

R13 fr 21: Ele teve um periodo muito dificil, ficou internado. Eu fui visitá-lo e nem acreditei que ele pudesse estar naquela situação, uma situação deplorável. Meu Deus do céu, naquele dia, a gente nem conseguiu dormir direito, de tão traumatizado que nós ficamos de vê-lo naquela circunstância.

R15 fr 89: Antes, o L. se tratava lá no hospital, mas ele tem pavor de lá. Então, era uma dificuldade, porque ele não ia. Porque o L. foi internado muitas vezes lá, então pegou horror ao hospital.

R9 fr 59: Porque na internação não tem amor. Eles dopam o paciente lá com medicamento para não dar trabalho, eu acho. Então dopam lá, porque não vão ter tempo para estar sentando e conversando, escutando. Porque eles falam demais, então tem que ter paciência.

A internação foi associada, pelos usuários, à desvalorização, reiterando a ideia de que as pessoas com transtornos mentais são incapazes de construir o seu cotidiano fora das instituições.

Ao ser internada, a pessoa adquire um novo status social, não apenas intramuros, e compreende que, ao sair da hospitalização, sua posição social no mundo externo nunca mais será a mesma (GOFFMAN, 2003).

O hospital psiquiátrico agrega desvalor à experiência humana. Não ajuda ninguém a se qualifcar. Quanto mais tempo alguém passa internado, tanto menos ele passa a valer na convivência com o seu grupo, em seu bairro. (VALENTINI, 2001, p. 14).

Inseridos em uma sociedade permeada pelo preconceito em relação à loucura, é possível que os próprios usuários assumam o discurso do senso comum, que desqualifica as pessoas com transtornos mentais. Este fato pode afetar-lhes a vida, a forma como eles se percebem e se sentem vistos pelos outros, influenciando na constituição da sua identidade. $\mathrm{O}$ usuário vive a contradição de se considerar uma pessoa capaz e o olhar da sociedade, que o rotula de incompetente para viver fora do hospital.

Ao ser internada, a pessoa passa por progressivas mudanças em suas crenças a respeito de si mesmo, e a respeito de outros, que são significativas para ele, compondo a sua 'carreira moral' (GOFFMAN, 2003).

U13 fr 38: Porque, na minha última internação, eu não conseguia nem ficar de pé. Ficava 
deitado e me olhavam, e falavam: "Tadinho, tâo novo". E hoje, eu já consigo vir ao CAPS, consigo ficar o dia.

U14 fr 20: Ai, tinha que trancar eles mesmo, porque tem gente que náo tem capacidade de tocar a vida sozinho. Se você dá dinheiro para eles, eles gastam de uma vez.

U14 fr 22: Tem gente que não tem condição de viver fora do hospital.

U14 fr 33: Ai, eu fiquei doente e fui para o hospital psiquiátrico. Lá era horrivel, né? Era assim, eles confundem muito a pessoa. Acham que é malandro...

Identifica-se, nos discursos dos entrevistados, que a atenção à saúde oferecida pelos hospitais psiquiátricos apresenta pouca resolutividade, pois, apesar de serem vistos como locais de albergamento para aqueles que não têm suporte social, isso náo resultou em relatos de benefícios em relação à saúde da pessoa com transtorno mental após as internaçóes.

Segundo Saraceno (2001, p. 20), as pessoas com transtornos mentais enfrentaram a situação de

\section{[...] violência e miséria nas instituiçóes psiqui-} átricas totais, abandono e respostas farmacológicas pesadas para os pacientes assim chamados ambulatoriais, êxitos dos tratamentos em longo prazo distribuidos entre melhoras, pioras e estabilidade.

A cronicidade e a presença dos manicômios são evidências concretas da impotência da psiquiatria no tratamento de pessoas com transtornos mentais (ROTELLI; LEONARDIS; MAURI, 2001, p. 26). O cuidado na comunidade tem melhor relação custo-efetividade do que o cuidado hospitalar de longa permanência (THORNICROFT; TANSELLA, 2010, p. 57).

As internaçóes por longo tempo ou o ciclo de reinternaçôes criam uma situação em que as pessoas com transtornos mentais não encontram melhora para a doença e levam uma vida 'arrastada' dentro do cotidiano institucional e no cotidiano de exclusão e desamparo quando estão na comunidade.

R7 fr 43: Ele [ex-marido] saía do hospital e entrava em crise de novo, ficava como indigente na rua, não tomava banho e comia lixo na rua, dos latóes de lixo. As internação não foi boa. Os doidos vão para o hospital de louco e sai de lá mais louco ainda. É verdade, eles saem mais louco de lá de dentro.

R3 fr 47: Quando a gente tava lá [hospital psiquiátrico], chegavam muitas pessoas em crise, né? Dava crise lá. Então, eu passava mal por isso. Eu penso: "Ai, meu Deus, porque as pessoas não ficam boas? Tomam o remédio direto e não ficam bom". Porque as pessoas dão o remédio e dão comida, dão café.

\section{O CAPS como uma alternativa ao hospital psiquiátrico}

Frente a essa dura realidade oferecida pelos hospitais psiquiátricos, a reforma psiquiátrica se organizou para propor uma nova possibilidade de pensar a loucura, de tratar e se relacionar com as pessoas com transtornos mentais. Nos discursos dos entrevistados, os CAPS se apresentam como uma substituição ao tratamento em internação hospitalar e concretizam uma nova forma de lidar com o transtorno mental.

Ocorre uma transformação institucional que reflete a forma de tratar os usuários, com o objetivo de reconstruir a pessoa e sua identidade social, estabelecendo-se condiçôes para que se torne um membro do corpo social. A tutela é substituída por uma relação de contato (BASAGLIA, 2005c, p. 248).

A oportunidade de se tratar em CAPS demonstra como as políticas de saúde interferem na vida cotidiana dos usuários e promovem novas 
possibilidades para as pessoas com transtornos mentais.

R9 fr 57: Precisa lutar para ter mais CAPS. Porque foi depois que surgiu estes CAPS que muita coisa melhorou. Porque antes era só internação. E a familia ficava longe e distante, $e$ não tinha um acompanhamento. Aqui tem. Eu falo aqui porque foi aqui que eu vi o resultado do meu filho.

U1 fr 39: Então [o CAPS] é uma chance de ter a parte de saúde bem próxima, náo é igual a um hospital, que se fica um monte de tempo lá e não se resolve nada.

R7 fr 42: No hospital psiquiátrico, ele não melhorava, não. Ele veio a melhorar no CAPS. Ai, começou a levar para o CAPS e ele começou a tomar injeção. e agora ele está bonito e gordo. Porque ele estava acabado, estava acabado.

Os entrevistados percebem nitidamente as diferenças entre o tratamento em regime de internação e o tratamento em CAPS. A atenção em CAPS apresenta alternativas de cuidado para as pessoas com transtornos mentais, previne internaçóes, inclui a família no tratamento, oferece liberdade de ir e vir e facilita a criação de uma rede social, além de outras tantas diferenças em relação aos hospitais psiquiátricos.

Diferentemente dos serviços fechados, que produzem isolamento, os serviços abertos caminham junto com a vida cotidiana (ROSA, 2008, p. 271). Segundo Heller (1982, p. 156) “[...] não há dúvida de que uma nova forma de vida deve colocar-se como objetivo encontrar um sentido da vida, completamente ou parcialmente desconhecido das geraçóes anteriores".

É função das políticas públicas de saúde oferecer possibilidades para o processo de desinstitucionalização das pessoas com transtornos mentais. Este processo pode começar com a

\section{[...] organização de equipes multiprofissio-} nais, cujo objetivo é acompanhar as pessoas, ajudando-as a construir autonomia e independência: arrumar-se, preparar alimentos, ler jornais, ouvir rádio e ver televisão, cantar, dançar, passear pela cidade, falar com as pessoas na rua, ir à igreja ou jogar futebol. (AMARANTE, 2007, p. 88).

Para os entrevistados, não há dúvidas de que a possibilidade de tratamento em CAPS proporciona uma melhora na qualidade de vida dos usuários e uma nova perspectiva para as pessoas com transtornos mentais.

As experimentaçóes de construção dos CAPS têm sido muito produtivas, para gerarem processos antimanicomiais; $e$, mais, têm de fato melhorado a vida de milhares de usuários desses serviços. (MERHY, 2007, p. 56).

R15 fr 95: Depois que ele veio para cá, para o CAPS, ele nunca mais foi internado. Que é ideal, porque aquelas internaçôes são horriveis, não adianta nada. Ele ficava um pouco lá e depois voltava pior para casa, bem pior. Então, eu estou achando ótimo.

U14 fr 12: Mas aqui não é um hospital, aqui é um CAPS, né?

U15 fr 35: É só conversar e avisar que vou ao Parque. Então tem dias de eu ir duas vezes ao Parque da Água Branca, uma de manhã cedo e outra de tarde. Então, eu não sou coagido, não sou preso, nada; sou uma pessoa livre. Graças ao CAPS, não a mim, ao CAPS.

Nem todos os usuários vivenciaram esta marca da internação hospitalar, mas, mesmo aqueles que não estavam internados, antes do tratamento em CAPS, permaneciam isolados em suas casas, nem sempre com uma assistência adequada.

É comum, mesmo quando o paciente não está internado, que ele continue a ser excluído. 
Se a ideologia manicomial está instaurada na sociedade, ela ultrapassa os muros do manicômio, e passa a ser concretizada nas relaçóes do paciente mesmo quando ele está fora da internação, na comunidade. (SALLES; BARROS, 2006, p. 414).

O CAPS tem cumprido a função de fazer uma ponte entre os usuários e a sociedade, realizando açôes e cuidado, rompendo com o isolamento, enfrentando preconceitos e promovendo a inclusão social.

U12 fr 29: A minha vida, antes de começar a frequentar o CAPS... Eu era uma pessoa triste. Não tinha amigos, não tinha ninguém para aconselhar, eu não tinha ninguém... Só ficava dentro de casa, fechado, com a janela fechada, com a porta do quarto trancada.

U17 fr 17: [Antes de frequentar o CAPS] Eu reclamava muito... Era muito fechado... Muito difícil, muito difícil para mim... Eu não sabia o que fazer, sem o tratamento no CAPS eu não sabia o que fazer... Ai, pronto, se fechava e se isolava... Fazia isso, achava isso, o jeito que vinha na minha cuca era fazer isso... É muito dificil para mim a vida, tudo praticamente, num...

Muitos dos usuários, principalmente os mais velhos, vivenciaram 'na pele' as transformaçóes ocorridas na atenção em saúde mental, passando de moradores de hospitais psiquiátricos e de constantes reinternaçóes para a possibilidade de se tratar e viver na comunidade. A mudança na vida cotidiana dessas pessoas é enorme, os usuários passaram de uma rotina institucional para o desafio de construir o seu próprio cotidiano na vida em sociedade.

"O atendimento no modo psicossocial, em especial nos CAPS, vem propiciando que os usuários se (re)insiram na sociedade, participem de diversas açôes sociais que não eram permitidas com o atendimento marcado pela institucionalização em hospitais psiquiátricos.

(NASI; SCHENEIDER, p. 1162).

O CAPS é um lugar de referência e tratamento para pessoas que sofrem com transtornos mentais, "[...] é um serviço de atendimento de saúde mental criado para ser substitutivo às internaçóes em hospitais psiquiátricos" (BRASIL, 2004, p. 13).

O fato dos serviços substitutivos ser uma estratégia central na atenção à saúde favorece a inclusão social das pessoas com transtornos mentais, que deixam de ser segregadas em instituiçôes fechadas para construir a sua vida na sociedade.

Os relatos ressaltam a importância das políticas públicas de saúde para a promoção da inclusão social e a transformação da vida cotidiana dessa população.

\section{Considerações Finais}

A partir dessas mudanças, a vida cotidiana dos usuários se transforma, e, da mesma forma que o contexto influencia a vida cotidiana, a vida cotidiana também pode direcionar transformações sociais. Com os usuários vivendo na comunidade, a população terá mais contato com essas pessoas. Eles buscam opções de trabalho, lazer, afetividade e começam a engendrar novas possibilidades de vida.

Ao pensar no cuidado da pessoa com transtorno mental é a vida cotidiana da pessoa que deve ser posta em foco, em toda a sua diversidade, complexidade e conflitos. No atual contexto, em que estão em ebulição tantas contradiçóes e em que os processos de inclusão parecem incertos perante o desafio de enfrentar uma história social secular de exclusão social, os CAPS se apresentam como um porto seguro, um lugar de acolhimento, o primeiro espaço social e subjetivo em que as pessoas com transtornos mentais podem ser quem são, estabelecer novas formas de relação e procurar caminhos para uma vida cotidiana em sociedade.

Frente à história de vida dos usuários que vivenciaram anos de internação, rompendo com laços 
sociais e sendo afetados pelo estigma em relação à doença mental, percebe-se que o CAPS promove avanços na inclusão social dessas pessoas e representa um espaço em que os usuários são aceitos e podem ser como são. Indica-se a necessidade de continuar a favorecer a inclusão social a partir dos desejos e escolhas do usuário - como estudar, trabalhar, ter amigos -, articulando o projeto terapêutico individual com as possibilidades de integração dessas pessoas na vida da comunidade.

\section{Referências}

AMARANTE, P. Saúde mental e atenção psicossocial. Rio de Janeiro: FIOCRUZ, 2007.

BARROS, S.; BICHAFF, R. Desafios para a desinstitucionalização: censo psicossocial dos moradores em hospitais psiquiátricos do Estado de São Paulo. São Paulo: FUNDAP, 2008.

BARROS, S.; EGRY, E. Y. O louco, a loucura e a alienação institucional: o ensino de enfermagem sub judice. Taubaté: Cabral Editora Universitária, 2001.

BASAGLIA, F. Um problema institucional: a exclusão como categoria sociopsiquiátrica. In: AMARANTE, P. (org.). Escritos selecionados em saúde mental e reforma psiquiátrica. Rio de Janeiro: Garamond, 2005a.

Corpo e instituição: considerações antropológicas e psicopatológicas em psiquiatria institucional. In: AMARANTE, P. (org.). Escritos selecionados em saúde mental e reforma psiquiátrica. Rio de Janeiro: Garamond, 2005b.

O circuito do controle: do manicômio à descentralização psiquiátrica. In: AMARANTE, P. (org.). Escritos selecionados em saúde mental e reforma psiquiátrica. Rio de Janeiro: Garamond, 2005c.

BORBA, L. O.; SCHWARTZ, E.; KANTORSKI, L. P. A sobrecarga da família que convive com a realidade do transtorno mental. Acta Paulista de Enfermagem, São Paulo, v. 21, n. 4, p. 588-594, 2008.

BRASIL. Ministério da Saúde. Secretária de Atenção à Saúde. Departamento de Ações Pragmáticas e Estratégicas. Saúde Mental no SUS: os centros de atenção psicossocial. Brasília: Ministério da Saúde, 2004.

COSTA-ROSA, A. O modo Psicossocial: um paradigma das práticas substitutivas ao modo asilar. In: AMARANTE, P. (org.). Ensaios: subjetividade, saúde mental e sociedade. Rio de Janeiro: FIOCRUZ, 2000.

DAVIS, F. A. Beyond hospital closure. In: BATES, P. (ed.). Working for inclusion: making social inclusion a reality for people with severe mental health problems. London: The Saintsbury Centre for Mental Health, 2002.

GOFFMAN, E. Manicômios, prisões e conventos. 7. ed. São Paulo: Perspectiva, 2003.

HELLER, A. Para mudar a vida: felicidade, liberdade e democracia. São Paulo: Brasiliense, 1982. Entrevista concedida a Ferdinando Adornato.

O cotidiano e a história. São Paulo: Paz e Terra, 2000.

NASI, C.; SCHNEIDER, J. F. O Centro de Atenção Psicossocial no cotidiano dos seus usuários. Revista da Escola de Enfermagem da Universidade de São Paulo, São Paulo, v. 45, n. 5, p. 1157-1163, 2011.

MERHY, E. E. Os CAPS e seus trabalhadores: no olho do furacão antimanicomial. Alegria e alívio como dispositivos analisadores. In: MERHY, E.E.; AMARAL, H. (orgs.). A reforma psiquiátrica no cotidiano II. São Paulo: Aderaldo \& Rothschild, 2007.

MORGAN, C. et al. Social Exclusion and Mental Health: conceptual and methodological review. The British Journal of Psychiatry, Londres, v. 191, p. 477-483, 2007.

ROSA, L. C. S. Transtorno mental e o cuidado na família. São Paulo: Cortez, 2008.

ROTELLI, F.; LEONARDIS, O.; MAURI, D. Desinstitucionalização, uma outra via. In: NICÁCIO, F. (org). Desinstitucionalização. São Paulo: Hucitec, 2001.

SALLES, M. M. Internação em hospital psiquiátrico: o (des)caminho para a vivência do cotidiano e da inserção social. 233f. 2005. Dissertação (Mestrado em Enfermagem Psiquiátrica) - Escola de Enfermagem, Universidade de São Paulo, São Paulo, 2005.

SALLES, M. M.; BARROS, S. O caminho do doente mental entre a internação e a convivência social. Revista Imaginário, São Paulo, v. 12, n. 13, p. 397-418, 2006. 
SALLES, M. M.; BARROS, S. •Transformações na atenção em saúde mental e na vida cotidiana de usuários: do hospital psiquiátrico ao Centro de Atenção Psicossocial

SARACENO, B. Libertando identidades: da reabilitação psicossocial à cidadania possível. Rio de Janeiro: TeCorá, 2001.

THORNICROFT, G.; TANSELLA, M. Boas práticas em saúde mental comunitária. Barueri: Manole, 2010.

TRIVIÑOS, A. N. S. Introdução à pesquisa em ciências sociais: a pesquisa qualitativa em educação. São Paulo: Atlas, 1987.
VALENTINI, W. Nenhum ser humano será bonsai. In: HARARI, A.; VALENTINI, W. (orgs.). A reforma psiquiátrica no cotidiano. São Paulo: Hucitec, 2001.

VIANNA, P. C. M.; BARROS, S. Análise do discurso: uma revisão teórica. REME: Revista Mineira de Enfermagem, Belo Horizonte, v. 7, n. 1, p. 56-60, 2003.

Recebido para publicação em abril/2012

Versão final em maio/2013

Conflito de interesse: não houve

Suporte financeiro: Pesquisa financiada pelo Conselho Nacional de Desenvolvimento Científico e Tecnológico, bolsa de doutorado no país (CNPa - n 141940/2010-7). A pesquisa também foi apoiada pelo Programa de Doutorado no País com Estágio no Exterior - PDEE, da CAPES - Coordenação de Aperfeiçoamento de Pessoal de Nível Superior (Processo no 3974-08-1; bolsa sanduiche). 